\title{
BJ

\section{DIGITAL TRANSFORMATION TECHNOLOGIES AS AN ENABLER FOR SUSTAINABLE LOGISTICS AND SUPPLY CHAIN PROCESSES - AN EXPLORATORY FRAMEWORK}

\section{Anna Lisa Junge} junge@logistik.tu-berlin.de Technische Universität Berlin, Chair of Logistics, Berlin, Germany.

\begin{abstract}
Goal: The aim is to present a literature review for identifying digital transformation technologies (DTT) for manufacturing and pointing out their capabilities and applications. Furthermore, the paper lays out an exploratory framework to depict the impact scope of the cases on logistics and supply chain management (L\&SCM) processes.

Design / Methodology / Approach: The identification of relevant DTTs and their capabilities is based on a systematic literature review. The exploratory framework builds upon Industry 4.0 concepts and frameworks as well as the conditions for sustainable digital artefacts. It is then related to cases found in the systematic literature review.

Results: The results indicate that the DTT auto identification, additive manufacturing, and cloud technology lead to improvements concerning transparency efficiency, optimizing distribution distances and logistics resources in networks. The framework presents an avenue for assessing the impact scope and potentials of implementing DTT.

Limitations of the investigation: The literature base limits the findings since it is built upon two databases and is restricted to articles published in English. The theoretically deduced framework accounts for the dimensions technologies, the SCOR model and RAMI architecture. The illustration is simplified but can be detailed according to the needs. It is not tested based on case studies and should therefore be applied in practice to further develop it.

Practical implications: Practitioners gain insight into how to anchor potential use cases for more sustainable L\&SCM processes in the framework.

Originality / Value: This paper is the first to relate the capabilities of DTT to more sustainable L\&SCM processes in manufacturing by means of a systematic literature review and link the findings to an exploratory framework.
\end{abstract}

Keywords: Digital Transformation Technologies; Logistics and Supply Chain Management; Sustainability; Manufacturing. 


\section{INTRODUCTION}

The term digital transformation is a subject that is widely discussed among practitioners, but also paths its way as a scientific discipline. It affects industries, people and organizations. Technology is seen as a major driver and enabler of digital transformation. Those digital transformation technologies (DTT) cause changes in value creation. Companies adapt their strategies, explore new business models, and focus on acquiring new skills and competences. The major goals of digital transformation are increased flexibility, more customer-centric processes, and cutting costs (Hofmann and Rüsch, 2017; Kersten et al., 2017; Ward et al., 2016).

Although DTTs are assumed to be an important driver for more efficient processes in L\&SCM for manufacturing companies, their definition remains vague (Schuh et al., 2016). Yoo et al. (2010) define digital technologies as having three important characteristics: (1) the reprogrammability, (2) the homogenization of data, and (3) the self-referential nature of digital technology. However, recent developments indicate that the capabilities of technologies relevant for digital transformation in L\&SCM go beyond the characteristics, as described by Yoo et al. (2010), since they also enable decentralized and autonomous processes (Hofmann and Rüsch, 2017). Publications concerning the improvement of processes by the means of DTTs are already available, but still very scarce. They mainly focus on efficiency improvement concerning cost and/or the discussion of the implementation of those technologies. The focus on more sustainability enabled by these technologies is an underrepresented research area. When searching for digital transformation or Industry 4.0 in combination with sustainability in September 2018, Business Source Complete yielded only one relevant result (Gružauskas et al., 2018). This fact points out that more research on the intersection of technologies, L\&SCM processes, and sustainability is needed.

This paper aims at giving an overview of DTT relevant for logistics and supply chain management in manufacturing. The characteristics of those technologies are presented and related to the areas discussed in the identified papers. The development towards integrated and connected logistics networks requires new assessments for technologies and their impact on the supply chains of manufacturing companies. The resulting research questions are: What are relevant DTTs for manufacturing and what are their capabilities and prospects concerning more sustainable L\&SCM processes?

The paper is structured as follows. First the research purpose is embedded in theory as well as literature and contextualized. Subsequently the methodology and the results from the systematic literature review are presented. The underlying cases found in literature are then categorized in an exploratory framework for the impact scope assessment of the technologies on sustainable L\&SCM processes. The conclusion and discussion section finalize the contribution.

\section{CONTEXTUALIZATION}

Current research about digital transformation and sustainability often focuses on the implications of DT on the three sustainability dimensions: economical, ecological and social sustainability (Beier et al. 2017; Kayicki, 2018). Beier et al. (2017) find that DT provides opportunities for the ecological dimension under the assumption that resource efficiency improvements can be realized. They highlight the impact of DT on the social dimension and the current challenges with regard to job replacement (Beier et al., 2017). According to Kayicki (2018), digital transformation in L\&SCM has not yet reached a maturity level; hence, sustainability implications will be improved and changed. The economical dimension of sustainability has the most important impact in the presented case study. This case study qualitatively maps the expected impacts of DT on the economical, ecological and social dimensions (Kayicki, 2018). Future research should elaborate new technological concepts focusing on opportunities created by digital transformation (Beier at al., 2017).

This paper intends to approach the aspect of DT for L\&SCM from a different angle: according to the Resource Based View, technologies represent a tangible resource that can be a competitive advantage for a company (Wernerfelt, 1984). In order to explore the possible competitive advantage of DTTs for a company with regards to sustainable L\&SCM, the prospects and the impact of their deployment need to be anchored to be described. As stated, DTTs show three unique characteristics: (1) the reprogrammability, (2) the homogenization of data, and (3) the self-referential nature (Yoo et al., 2010). DTTs represent digital artefacts that should feature four characteristics in order to be sustainable digital artefacts. The first one is the elaborateness determined by modularity, integrity, accuracy, robustness, and other characteristics regarding the quality of their substance. Second, they should have transparent structures signifying technical openness. Third, semantic information helps to make DTTs easily intelligible to humans and machines through comprehensible structures and metadata. Fourth, distributed location means that that DTTs and associated data are stored and operated on multiple sites, e.g. through replicated data storage or peer-to-peer technology (Stuermer et al., 2017). Many DTT characteristics that need to be met in order to represent a sustainable digital artifact require reference architecture for assessing the impact of technologies on businesses and supply chains. The 
Brazilian Journal of Operations \& Production Management

Volume 16, Número 3, 2019, pp. 462-472

DOI: 10.14488/BJOPM.2019.v16.n3.a9 development of the exploratory framework presented in this paper intends to provide such a frame and to anchor the cases found in literature to better understand the focus of current research and to provide avenues and applications for research and practice.

\section{METHODOLOGY}

The systematic literature review follows the approach to first identify the research field, then construct the Boolean phrase for the literature search and identify suitable databases, define inclusion and exclusion criteria, and then analyze the literature and summarize results (Durach et al., 2017).

"To answer the first research question, a systematic literature analysis was conducted in May 2018. The Boolean phrase (digital* OR Industry 4.0 OR smart) AND (logistic* OR SCM OR Supply Chain Management OR Supply Chain* OR SC) AND technolog* AND (manufacturing industr* OR operation*)was used to search through two databases (Business Source Complete and Web of Science) and was applied to title, abstract and keywords. The two databases cover a range of journals relevant for manufacturing, logistics and supply chain management and are thus considered to be apt for answering the research question. Despite the care taken in the systematic literature review, the language (English), the selected keywords, and the selected databases represent a natural limitation. Inclusion criteria for the papers are:

- Relevance for the manufacturing industry with multi-variant production. This excludes publications covering process industries such as oil, gas and electricity.

- Focus on logistics and supply chain management.

- Discussion of the implementation or use of a concept or technology with regard to logistics and supply chain management and/or description of a classification/meta-analysis of digital transformation with relevance for logistics and supply chain management.

The results of the systematic literature analysis are displayed in figure 1 , showing that 62 papers represent the basis for further consideration (Junge, 2020).

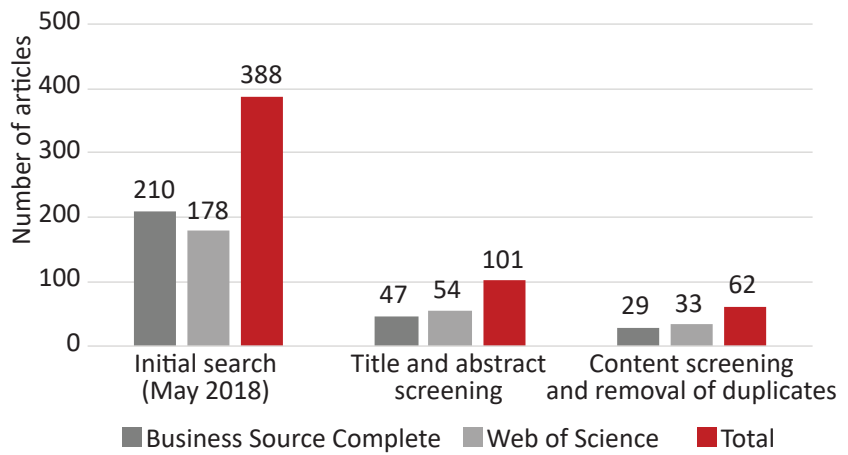

Figure 1. Results of systematic literature analysis Source: Junge, 2020

"The remaining papers are published more often in production and manufacturing journals (e.g. International Journal of Production Research) than those in logistics and supply chain management. They have different emphases representing the wide range of this interdisciplinary research topic.The papers were subsequently analyzed and investigated with regard to the technologies covered (applicable to all 62 papers) and then with a focus on sustainability. Six out of the 62 papers address sustainability aspects, representing $9.7 \%$ (Junge, 2020).

The method for constructing the framework is as follows: the implications of the literature review are taken as input to define the potentials of technologies as enablers for sustainable L\&SCM processes. Furthermore, relevant frameworks for the subject are presented, compared and adapted to a framework fitting the requirements of L\&SCM in manufacturing.

\section{RESULTS FROM THE SYSTEMATIC LITERATURE REVIEW}

The literature analysis reveals that technologies for collecting data, integrating it and finally putting it to value are the basis for digital transformation in logistics. The resulting technologies are information and communication technologies, auto identification technologies and cloud for integrating data and making it visible. This is the first step to create transparency about processes and assets. Based on transparency analytics, blockchain and cyber-physical systems, decentralized and semi-autonomous decisions and processes can be made. For completely autonomous processes with cognitive abilities, automation technologies combined with analytics are relevant. Further technologies supporting autonomous logistics are virtual and augmented reality as well as additive manufacturing. Those are the technologies found in the systematic literature review being an enabler for increasingly integrated planning and steering of logistics networks. The results show that digital transformation goes beyond the logic of digital representation as postulated by 
Yoo et al. (2010). Technologies in combination with processes, organization and people enable new capabilities such as decentralized and (semi-) autonomous decision making as well as initiated automated tasks.
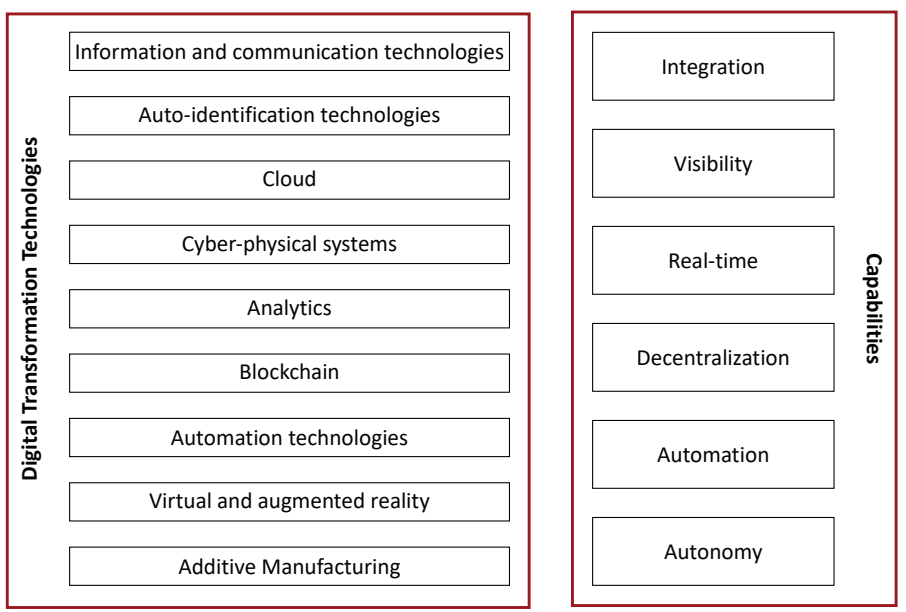

Figure 2. Digital transformation technologies and their capabilities in logistics and supply chain management Source: Junge, 2020

When analyzing the literature, it can be stated that the papers lay out several success factors as well as barriers for the implementation of DTTs. Success factors mean the need to test technology in practice to learn from the resulting implications and the issue that people-related factors, such as managerial skills, tend to play the strongest role in value creation caused by information technology (Dighero et al., 2005; Dong et al., 2009). Potentials are the offering of more adaptable and flexible supply chain services tailored to customer needs based on data, leading to more agile supply chains (Janssen and Feenstra, 2010). A prerequisite for modular L\&SCM are service oriented architectures running on information technology infrastructure that fits organizational needs. Digital transformation will lead to a paradigm shift that is comparable to the shift in software development from structured to object oriented development. This shift will foster the development of new and adapted ontologies for specific requirements and problems in L\&SCM (Ameri and Patil, 2012; Kim and Laskowski, 2018; Lu and Ju, 2017; Prause and Weigand, 2016; Zhang et al., 2011).

Existing barriers for the targeted and efficient use of DTTs lack communication standards (Doh et al., 2016), hampering integration (Holmqvist and Stefansson, 2006), insufficient flexibility of intra- and inter-organizational business processes (Seethamraju, 2008), and the current status of many companies not yet disposing of the basic requirements for digital transformation, such as data availability and validity (Bogner et al., 2016).

An unanswered question so far is whether the primary aim of digital transformation - increasing flexibility while decreasing costs - will lead to a reduction or rise of complexity. On the one hand, planning and steering can be simplified; on the other hand, increasing data, e.g. by tracking and tracing on a more detailed level, will impose new challenges for integration and control mechanisms. More decentralized production, for example, enabled by additive manufacturing, can lead to more or less supply chain stages, as discussed by Baumers et al. (2017) and Durão et al. (2017). This can also have an impact on sustainable processes and products concerning L\&SCM in manufacturing. The papers found in the systematic literature analysis, focusing on sustainability aspects in L\&SCM, are briefly presented and then clustered according to figure 2 .

When assessing the different papers that build the basis for the literature analysis, it is surprising that a clear focus lies on additive manufacturing. This is an enabler for more decentralized and customer-focused production since it allows, for example, customized on-demand production of certain parts, which can be very relevant for spare parts management. The paper of Baumers et al. (2017) investigates the advantages and disadvantages of centralized versus decentralized supply chains. They highlight the need for further investigating the environmental consequences of supply chain settings. According to the authors, centralized supply chains enable more efficient manufacturing processes, reduced inventory and reduced requirements for distribution. Potentials of decentralized supply chains lie in envi-

Table 1. Overview of papers covering sustainability aspects

\begin{tabular}{|c|c|c|c|c|}
\hline No. & Author & Journal & Technologies & Capabilities \\
\hline A & Baumers et al. (2017) & Journal of Industrial Ecology & Additive Manufacturing & Decentralization \\
\hline B & Bechtsis et al. (2017) & Journal of Cleaner Production & Automation technologies & Autonomy \\
\hline C & Cerdas et al. (2017) & Journal of Industrial Ecology & Additive Manufacturing & Decentralization \\
\hline D & Guo et al. (2017) & Applied Sciences & $\begin{array}{c}\text { Automation technologies, Cloud } \\
\text { Computing }\end{array}$ & Real-time, Autonomy \\
\hline E & Tien (2012) & $\begin{array}{c}\text { Journal of Systems Science and } \\
\text { Systems Engineering }\end{array}$ & $\begin{array}{c}\text { Analytics, Additive Manufactur- } \\
\text { ing }\end{array}$ & Real-time, Autonomy \\
\hline F & Zhang et al. (2016) & $\begin{array}{c}\text { International Journal of Produc- } \\
\text { tion Research }\end{array}$ & $\begin{array}{c}\text { Cloud Computing, Auto-identifi- } \\
\text { cation technologies }\end{array}$ & Real-time \\
\hline
\end{tabular}


ronmental savings in terms of transportation and handling of intermediate and end products. As a conclusion, they state that the use of additive manufacturing can enable new configurations for distribution. This can result in sustainability impacts; however, possible rebound effects need to be taken into consideration as well (Baumers et al., 2017).

Cerdas et al. (2017) also investigate the impact of additive manufacturing on L\&SCM. They focus on environmental impacts when using additive manufacturing in a distributed manufacturing system. A special emphasis is put on the product lifecycle, which is compared to a traditional centralized manufacturing system. Their results reveal that it cannot be clearly stated whether the distributed manufacturing systems show advantages compared to the centralized one. The energy efficiency of the respective production process, the regional electricity mix, the material used and user experience, the quality of the printed product and the rebound effects prevention affect the potentials of achievable sustainability impacts (Cerdas et al., 2017).

Tien (2012) discusses additive manufacturing combined with cloud computing and analytics to enable co-produced mass customization. According to the author this can lead to less offshoring, because products are co-produced locally allowing a more effective and efficient production. Such a development can shift the initiating event for production, from raw material supply to customer demand (Tien, 2012).

Initiating processes are also in the scope of investigation for the paper by Guo et al. (2017). They simulate the use of automation technologies combined with a cloud service platform to actively publish or request logistics tasks. Their results, achieved through the application of colored Petri nets, show that their approach outperform the event-driven method concerning energy consumption. (Guo et al., 2017)

Bechtsis et al. (2017) developed a framework for corporations to consider automated guided vehicles in a structured manner, including decision support for economic, environmental and social sustainability. They subdivide each of the sustainability dimensions on an operational, tactical and strategical echelon. The findings in literature reveal points important for L\&SCM decisions according to the proposed framework. Their findings demonstrate a lack of research across the end-to-end supply chain. The main focus lies on warehouse, manufacturing and distribution operations (Bechtsis et al., 2017).

Zhang et al. (2016) choose the use of smart auto-identification enabled boxes as an analysis unit combined with a cloud service platform used for collaboration. In their setting a third party logistics provider is the owner of the smart boxes and manages their maintenance, status monitoring, information management, and recycling. The application of an optimization method shows that the use of the smart boxes leads to advantages concerning loading rate, reducing distribution distances, and optimizing logistics resources. The smart boxes are an example for a hybrid service bundle (product service system) that can enable a more sustainable, green low carbon distribution pattern. The resulting advantages are maximized revenue for all stakeholders, reduction of the use of natural resources, and increased logistics efficiency (Zhang et al., 2016).

The following figure summarizes and represents the findings of the systematic literature analysis. It can be stated that the discussed papers cover the capabilities real-time, decentralization, and autonomy for enabling more sustainable L\&SCM processes in manufacturing.
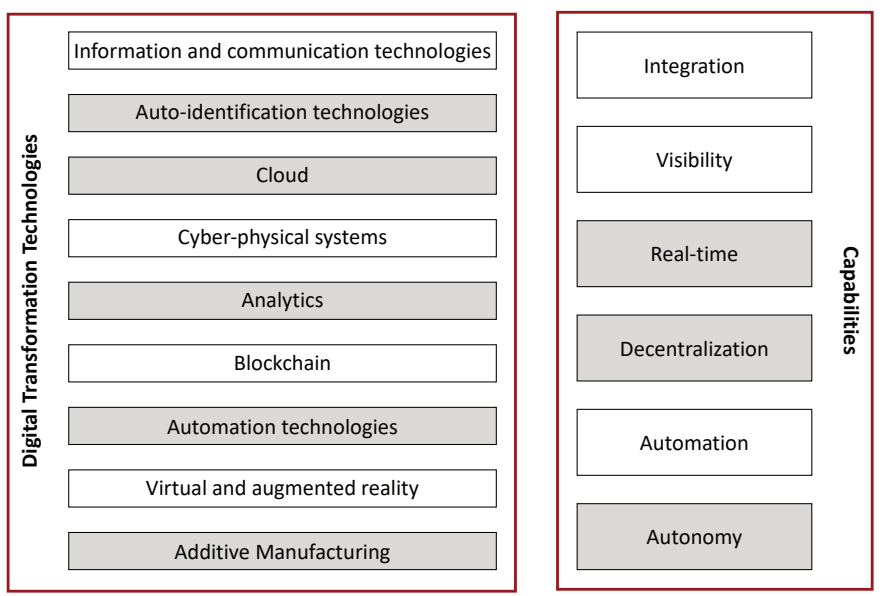

Figure 3. Technologies and capabilities covered by papers with a focus on sustainability

Source: Junge, 2020

As a second step, it is worthwhile to put these findings in a wider context and to anchor the discussed approaches in a framework. Therefore, in the following steps, different frameworks with relevance for Industry 4.0, manufacturing, L\&SCM, and sustainability are presented and discussed. Based on that evaluation, a framework that allows classifying the presented cases is deduced.

\section{AN EXPLORATORY FRAMEWORK FOR THE IMPACT SCOPE ASSESSMENT OF DTT ON MORE SUSTAINABLE L\&SCM PROCESSES IN MANUFACTURING}

To develop a framework for describing the impact of DTT on more sustainable L\&SCM processes in manufacturing, different already existing frameworks with relevance for the subject are briefly presented. The basis for this evaluation is displayed in the following table. 
Table 2. Overview of considered frameworks and conceptualizations with regard to L\&SCM 4.0

\begin{tabular}{|c|c|c|c|c|c|}
\hline No. & Author & Theme & Focus & $\begin{array}{l}\text { Research } \\
\text { subject }\end{array}$ & Results/ Implications \\
\hline 1 & $\begin{array}{l}\text { Kayicki } \\
\text { (2018) }\end{array}$ & $\begin{array}{l}\text { Sustainability } \\
\text { impact of } \\
\text { digitization on } \\
\text { logistics } \\
\end{array}$ & $\begin{array}{l}\text { Impact of digitalization char- } \\
\text { acteristics on sustainability } \\
\text { criteria }\end{array}$ & $\begin{array}{l}\text { FMCG company } \\
\text { and transport } \\
\text { providers }\end{array}$ & $\begin{array}{l}\text { The sustainability aspect of digitization with } \\
\text { respect to economic implications is more im- } \\
\text { portant than the dimensions of environmental } \\
\text { and social sustainability }\end{array}$ \\
\hline 2 & $\begin{array}{l}\text { Hofmann } \\
\text { and Rüsch } \\
\text { (2017) }\end{array}$ & $\begin{array}{l}\text { A logistics-ori- } \\
\text { ented Industry } \\
4.0 \text { application } \\
\text { model }\end{array}$ & $\begin{array}{l}\text { Interrelation of material } \\
\text { flow and information flow }\end{array}$ & $\begin{array}{l}\text { Logistics man- } \\
\text { age-ment in } \\
\text { manufacturing } \\
\text { companies }\end{array}$ & $\begin{array}{c}\text { Potentials include } \\
\text { • Improved demand assessment } \\
\text { - Dynamic and more efficient milk run } \\
\text { • Shortened cycle times } \\
\text { • Reduced bullwhip effects } \\
\text { - Highly transparent and integrated supply } \\
\text { chains } \\
\text { - Improvements in production planning }\end{array}$ \\
\hline 3 & $\begin{array}{l}\text { Strandhagen } \\
\text { et al. (2017) }\end{array}$ & $\begin{array}{l}\text { Logistics } 4.0 \\
\text { and emerging } \\
\text { sustainable } \\
\text { business } \\
\text { models }\end{array}$ & $\begin{array}{l}\text { Implications of Logistics } 4.0 \\
\text { trends on value proposition, } \\
\text { customer interface, supply } \\
\text { chain structure and the } \\
\text { financial model plus sustain- } \\
\text { ability dimensions } \\
\end{array}$ & Business models & $\begin{array}{c}\text { Potentials for manufacturing companies include } \\
\text { - Increase in material productivity, resource } \\
\text { efficiency and waste reduction } \\
\text { - More sustainable production processes } \\
\text { - Shared resources for better asset utilization }\end{array}$ \\
\hline 4 & $\begin{array}{l}\text { Brettel et al. } \\
\qquad(2014)\end{array}$ & $\begin{array}{l}\text { Identification } \\
\text { of Industry } \\
4.0 \text { research } \\
\text { streams }\end{array}$ & $\begin{array}{l}\text { Cluster analysis of research } \\
\text { papers published with } \\
\text { regard to Industry } 4.0\end{array}$ & $\begin{array}{l}\text { Manufacturing } \\
\text { companies }\end{array}$ & $\begin{array}{l}\text { The main research streams are: } \\
\bullet \text { Individualization of production } \\
\text { • Horizontal integration into collaborative } \\
\text { networks } \\
\text { • End-to-end digital integration }\end{array}$ \\
\hline 5 & $\begin{array}{l}\text { Adolphs et } \\
\text { al. (2015) }\end{array}$ & $\begin{array}{l}\text { Reference } \\
\text { Architecture } \\
\text { Model Indus- } \\
\text { try (RAMI) } 4.0\end{array}$ & $\begin{array}{l}\text { Layers and hierarchy levels } \\
\text { representing the architec- } \\
\text { ture of assets and informa- } \\
\text { tion in smart factories }\end{array}$ & $\begin{array}{l}\text { Manufacturing } \\
\text { companies }\end{array}$ & $\begin{array}{l}\text { - Description of interrelations of devices and } \\
\text { information architectures } \\
\text { - Framework to allow categorizing different } \\
\text { impacts and hurdles (e.g. integration, } \\
\text { standardization) } \\
\text { - Allows description of functional relations } \\
\text { - Value stream only focuses on the product itself }\end{array}$ \\
\hline
\end{tabular}

The work presented by Kayikci (2018) is the one closest to the theme of this research since it focuses on digitalization in logistics with a focus on sustainability. The author proposes a sustainable logistics ecosystem, including digitalization enablers, characteristics of digitalization in logistics, technologies and applications, as well as sustainability dimensions. The first three impact end-to-end supply chains result in certain effects concerning sustainability. Therefore, a set of sustainability criteria in the dimensions of economy, environment and society is proposed to evaluate the impacts of digitalization characteristics. This is a qualitative assessment leading to the result that the economic implications were rated as more important than the other two dimensions. Especially in terms of logistics cost, delivery time, delay, inventory, reliability and flexibility issues, a great potential was seen by case study participants. It is also stated that digitalization in L\&SCM has not yet reached a maturity level to assess the impacts on a quantitative basis (Kayikci, 2018).

Hofmann and Rüsch (2017) state that Industry 4.0 is expected to achieve opportunities in terms of decentralization, self-regulation, and efficiency. They are based on the digitalization framework by Fleisch et al. (2014) and an application model adapted for logistics is designed. According to this application model, the value of logistics 4.0 lies in the value of availability of data (transparency about the physical supply chain and its processes), combined with the value of digital services. Hybrid service bundles can be an opportunity for increased customer value. Within their research the authors qualitatively investigated just-in-time/just-in-sequence delivery as well as the Kanban concept. Concerning just-intime/just-in-sequence, the new scenario consists of production planning based on real-time consumption data and demand patterns and an integrated cloud-based ERP system for the end-to-end supply chain. This enables suppliers to plan their disposition and production based on real-time data and delivery with end-to-end route optimization. They found that reduced bullwhip effects, highly integrated supply chains, and improvements in production planning are among the potential benefits. The modified cross-company Kanban cycle, according to the Industry 4.0 scenario, consists of intelligent bins for demand assessment transmitting a digital real-time Kanban-signal linked to the supplier's disposition and production. Collection and delivery takes place via a demand-oriented milk run and the goods receipt at the buyer is carried out via an auto-identification barrier or 
scanning device. Hence, an improved demand assessment, dynamic and more efficient milk run milk run $s$ as well as shortened cycle times can be expected (Hoffmann and Rüsch, 2017). The potential capabilities pictured by Hoffman and Rüsch coincide with the findings of the literature review in this paper. The capabilities as depicted in figures 2 and 3 are more extensive as they complement decentralization, self-regulation (autonomy) and real-time by visibility, integration and automation. The customer value and potential efficiency gains of these capabilities for L\&SCM need to be taken into account as well, as they are a prerequisite for achieving potentially autonomous processes in L\&SCM.

Strandhagen et al. (2017) explore Logistics 4.0 and emerging sustainable business models. They investigate implications of Logistics 4.0 trends on value proposition, customer interface, supply chain structure and the financial model, and they also include the three sustainability dimensions. Logistics 4.0 trends encompass individualization, Servitization, accessibility, autonomy, global networks, green logistics, and sharing economy. The two last mentioned trends account for sustainability aspects and partly conflict with other trends, such as individualization. Concerning the changing value proposition, Strandhagen et al. (2017) also stress the shift towards service orientation instead of product orientation. This materializes in the fact that value creation focuses on functionality, solutions, license to use the products, and applications. Furthermore, the customer receives more personalized products and services augmenting the perceived value to the customer. The customer interface will change as well, since customers will increasingly be integrated into the design of products and services. This allows a new relationship with the customer, which can foster long-term relationships. Supply chain structures are susceptible to change towards the sharing of resources and a total systems approach to manage the flow of information and material. New technologies allow the creation of virtual and more adaptable supply chains. The implications within the sustainability dimensions are described as an increase in material productivity, resource efficiency and waste reduction, more sustainable production processes, and shared resources for better asset utilization. The new customer interface can enable a new awareness for products and services (encouragement of sufficiency). The authors discuss that the conflicting objectives of the logistics 4.0 trends, as well as the possible rebound effects of technology use need to be taken into account, but that they see potential for the impact of the mentioned trends with regard to sustainability. Sustainability development in turn can also impact the formation of trends, e.g. through customer pressure to shift the focus to collaboration and sharing solutions in logistics (Strandhagen et al., 2017).

Brettel et al. (2014) have analyzed eight scientific journals with regards to the following research fields: individualized production, end-to-end engineering in a virtual process chain, and production networks. They then applied a cluster analysis to assign topics to the research fields. The findings are enriched by structured interviews with managers from industry, as well as from consulting. They found several topics within the three research streams. The one directly linked with sustainability is collaborative consumption linked to horizontal integration in collaborative networks. Out of the 548 articles being part of the cluster analysis, 106 belong to the category of collaborative networks. Further findings of the cluster analysis reflect the capabilities as described in the previous literature analysis as well as the importance of servitization. A primary challenge will remain to incorporate flexibility into mass production to account for the requirement of individualized products. This is also valid for modular L\&SCM services and processes (Brettel et al., 2014).

The RAMI 4.0 is an attempt to present an architecture model to serve as a basis to describe informational and physical relations within the smart factory. On the one hand side, it helps describing process changes caused by Industry 4.0. On the other hand, is serves as a basis for standardization. It is developed for a manufacturing context, but can be adapted for L\&SCM purposes. The hierarchy levels already include a network of enterprises and the informational layer, which is based on IEC62264, and IEC61512 is also valid for the L\&SCM processes of manufacturing companies. The only part restricting the applicability of the RAMI 4.0 for end-toend supply chains is its inherent value stream, which only depicts a product's value stream. However, the importance of L\&SCM in this context is recognized by stating that the data used in assembly can help intralogistics organizing itself on the basis of the order backlog. Purchasers can see in real time the position of vendor parts. Customers can track the status of their order and where it is in the manufacturing process. Linking the connectivity potentials to integrate purchasing, order planning, assembly, maintenance, customers, and suppliers generates great potential for improvement. Therefore, the complete value network has to be considered and not only the factory in isolation. This includes suppliers, engineering, production, and customers plus logistics service providers. (Adolphs et al., 2015)

A meaningful addition to the RAMI 4.0, from a L\&SCM perspective, is the Supply Chain Operations Reference (SCOR) model. The SCOR model is used by science and practitioners alike. It is a model that describes the different levels of logistics processes and is also used for modeling IT processes in L\&SCM (Bolstorff et al. 2007). For the purpose of describing the anchoring of the presented cases for DTTs potentials for more sustainable L\&SCM processes in manufacturing, the first level is sufficient, also due to the hitherto limited number of included papers and its presented cases. 

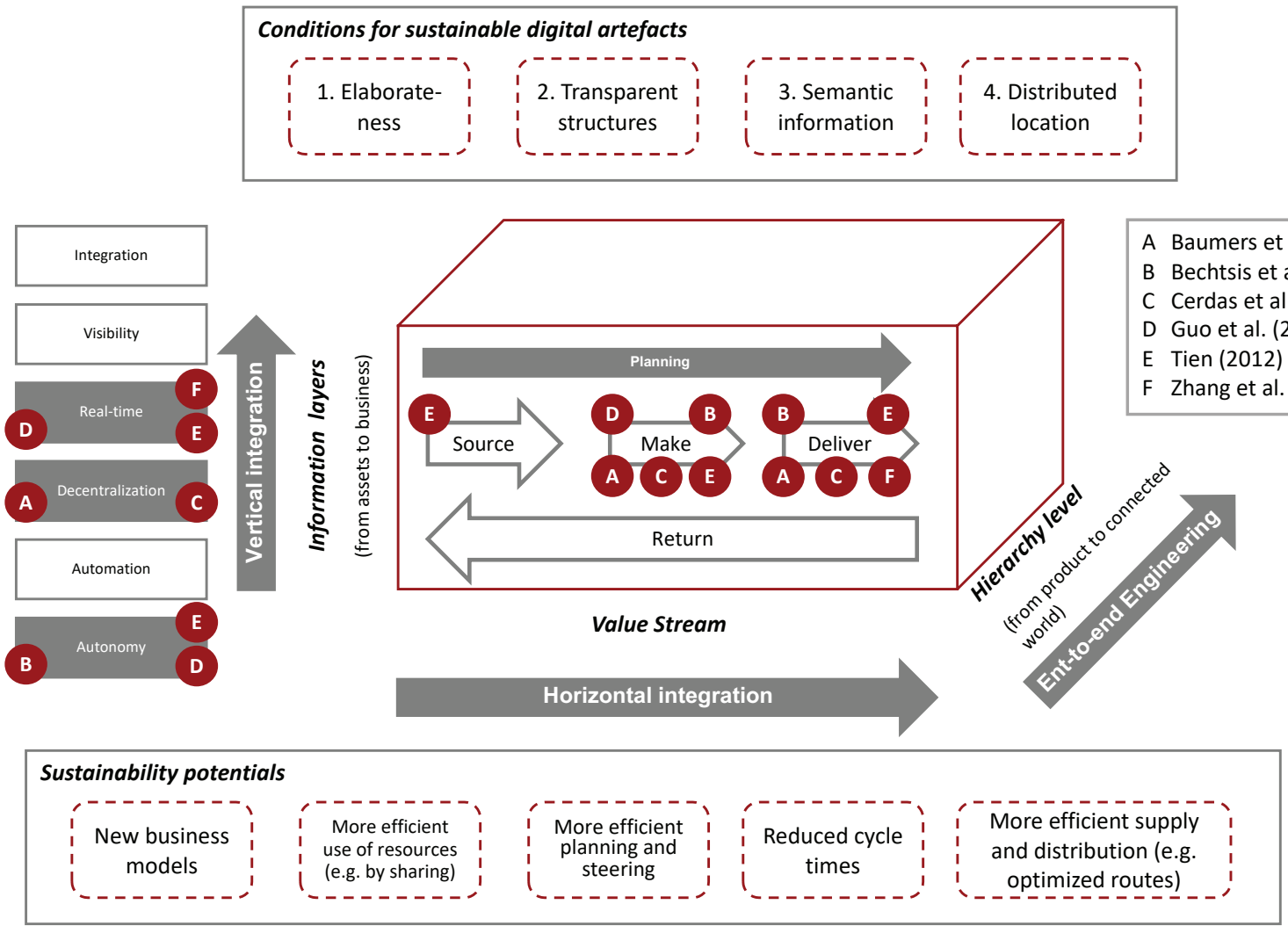

Figure 4. Framework for describing the impact scope of DTT in manufacturing for sustainable L\&SCM

The framework proposed in figure 4 builds upon the findings previously elaborated. It depicts the DTTs' enabled capabilities as well as the representation of the RAMI 4.0 (information layer, hierarchy level and value stream) with the end-to-end supply chain, which is affected by the DTTs. The categorization of the papers found in the systematic literature review shows that their focus mainly lies on production and delivery. Sourcing and returning are not yet in the focus of academic research with regard to the impact of DTTs on sustainability in L\&SCM, although Zhang et al. (2016) briefly mention return processes. The six considered papers also support the fact that the sustainability dimension "economy" is the most relevant in academic research (e.g. Bechtsis et al., 2017). The information layers and hierarchy levels are deliberately not detailed any further, as this analysis would have been small-sized for the number of cases (papers) at hand. However, once the amount of research papers in this area increases, the distinction between informational layers and hierarchical levels can be useful to further differentiate the impact scope of DTTs in an L\&SCM context for manufacturing. This would add two additional impact scope dimensions to the assessment. Table 3 depicts a broad analysis of the six cases found in literature for the three axes, information layer, value stream, and hierarchy level. Additionally, it is displayed whether the conditions of sustainable digital artefacts (1-4) are met or not.

The presented framework adds two important angles for the assessment and anchoring of cases for sustainable L\&SCM processes in manufacturing to the existing RAMI 4.0. First, it includes the value stream based on the SCOR model and second it includes the conditions for digital artefacts to the technical representation of business and hierarchy layers. Implications for research and practice are depicted in the following section.

\section{CONCLUSION AND DISCUSSION}

The research area of digital transformation in L\&SCM is currently evolving. As there is still no clear understanding about the concrete implications, this exploratory research paper intends to give insights into more sustainable L\&SCM processes in manufacturing enabled by DTTs. The systematic literature analysis offers a snapshot of subjects currently under investigation in scientific literature. Results show that the prospects of DTTs concern optimization of transportation distances, reduction in energy consumption and optimizing logistics resources. These findings mainly concern the 
Table 3. Analysis of the literature cases with regard to their impact scope in manufacturing network

\begin{tabular}{|c|c|c|c|c|}
\hline Case & Information layer & Value Stream & Hierarchy level & $\begin{array}{c}\text { Conditions of } \\
\text { digital artefacts }\end{array}$ \\
\hline A & Business layer & Make, Deliver & Connected World & Yes \\
\hline B & Business layer & Make, Deliver & Enterprise & Not applicable \\
\hline C & Business layer & Make, Deliver & Connected World & Yes \\
\hline D & $\begin{array}{c}\text { Information and func- } \\
\text { tional layer }\end{array}$ & Make & Work units & Yes \\
\hline E & Business layer & Source, Make, Deliver & Connected World & Yes \\
\hline F & $\begin{array}{c}\text { Information and func- } \\
\text { tional layer }\end{array}$ & Deliver & Work units & \\
\hline
\end{tabular}

environmental sustainability dimension. Solely the decision making framework, as proposed by Bechtsis et al. (2017), includes all three sustainability dimensions. The social dimension of sustainability is clearly underrepresented.

The proposed framework for anchoring the impact scope of the cases found in literature shows that they mainly focus on production and delivery. For a more holistic perspective, the end-to-end supply chain should be put into focus, as it is also encouraged and performed by Kayikci (2018). The anchoring of the cases to the axes of the framework, as displayed in table three, shows that the focus of the observed cases mainly can be related to the business layer and the hierarchy level of the connected world. This is inherent to L\&SCM. The two cases, D and F, at the work unit level describe concrete cases that also depict challenges concerning the integration of more sustainable and technologically enabled processes. With more practical cases both from literature and case studies, the framework can be further developed and improved. It also allows a more comprehensive investigation using a more detailed level of the SCOR model.

Analysis of the six cases show that an end-to-end perspective is not yet included; return processes are out of focus. This hampers the detection of sustainability potentials concerning closed loop supply chains. Additionally, avenues for research lie in three areas: first conceptualizing the impacts of DTTs for sustainability; second, relating and further developing the conditions for sustainable digital artefacts for L\&SCM, and third, developing practical methods and tools for practitioners to assess the sustainability impact of their technology deployment. The first two research avenues are a prerequisite for the third one. The conditions for digital artefacts should be enriched by the ecological and social ones. As standardization projects for end-to-end integration of engineering in real-time connected value networks are currently pursued, this is a tremendous chance to also include the sustainability focus in a stronger way. The framework proposed in this contribution offers a first orientation for those avenues. Practitioners benefit from the framework in two ways: they can test whether their DTTs' deployment fulfill the conditions of digital artefacts and can link them to the hierarchy and information layers. This is especially helpful, when describing challenges with regard to the implementation of DTTs for more sustainable L\&SCM processes, e.g. in the information layers with regard to data integration and communication. These challenges should be captured in a structured manner with the sustainability focus in mind. This would help developing purposefully the digital artefacts, which also give indications for policy maker concerning standardization needs and areas for funding, in order to reap the benefits of DTT for a more sustainable and just deployment. This is especially linked to open data and software, as well as social implications of technology use in value networks.

There are several limitations to this exploratory research approach. First, the systematic literature analysis is only based on two databases and on English literature, which might have excluded other relevant papers. Second, the proposed framework should be complemented and enriched by primary case studies to further understand the impacts of DTTs on more sustainable L\&SCM processes in manufacturing and to develop a conceptualization of the sustainability potentials of DTTs. The six literature-based cases are a limitation for the analysis and conclusion; therefore, in the future, a database with cases of primary and secondary nature should be established.

\section{REFERENCES}

Adolphs, P. et al. (2015), "Referenzarchitekturmodell Industrie 4.0 (RAMI4.0)“, VDI/VDE-Gesellschaft Mess- und Automatisierungstechnik, ZVEI.

Ameri, F. and Patil, L. (2012), "A semantic web-based framework for agile supply chain deployment", Journal of Intelligent Manufacturing, Vol. 23, No. 5, pp. 1817-1832.

Baumers, M. et al. (2017), "Charting the Environmental Dimensions of Additive Manufacturing and 3D Printing", Journal of Industrial Ecology, Vol. 21, No. S1, pp. S9-S14.

Bechtsis, D. et al. (2017), "Sustainable supply chain management in the digitalisation era - The impact of Automated 
Guided Vehicles", Journal of Cleaner Production, Vol. 142, No. 4, pp. 3970-3984.

Beier, G. et al. (2017), „Sustainability Aspects of a Digitalized Industry - A Comparative Study from China and Germany", International Journal of Precision Engineering and Manufacturing-Green Technology, Vol. 4, No. 2, pp. 227-234.

Bogner, E. et al. (2016), "Study Based Analysis on the Current Digitalization Degree in the Manufacturing Industry in Germany", Procedia CIRP 57, pp. 14-19.

Bolstorff, P. A. et al. (2007). Spitzenleistungen im Supply Chain Management - Ein Praxishandbuch zur Optimierung mit SCOR, Springer, Berlin, Heidelberg.

Brettel, M. et al. (2014), "How Virtualization, Decentralization and Network Building Change the Manufacturing Landscape: An Industry 4.0 Perspective", International Journal of Information and Communication Engineering, Vol. 8, No. 1, pp. 37-44.

Cerdas, F. et al. (2017), "Life Cycle Assessment of 3D Printed Products in a Distributed Manufacturing System", Journal of Industrial Ecology, Vol. 21, No. S1, pp. S80-S93.

Dighero, C. et al. (2005), "RFID: The Real and Integrated Story", Intel Technology Journal, Vol. 9, No. 3, pp. 247-257.

Doh, S. et al. (2016), "Systems Integration in the Lean Manufacturing Systems Value Chain to Meet Industry 4.0 Requirements", Transdisciplinary Engineering: Crossing Boundaries, Proceedings of the 23rd ISPE Inc. International Conference of Transdisciplinary Engineering, pp. 642-650.

Dong, S. et al. (2009), "Research Note - Information Technology in Supply Chains: The Value of IT-Enabled Resources Under Competition", Information Systems Research, Vol. 20, No. 1 , pp. 18-32.

Durach, C. et al. (2017), "A New Paradigm for Systematic Literature Reviews in Supply Chain Management", Journal of Supply Chain Management, Vol. 53, No. 4, pp. 67-85.

Durão, L. F. C. S. et al. (2017), "Additive manufacturing scenarios for distributed production of spare parts", The International Journal of Advanced Manufacturing Technology, Vol. 93, No. 1-4, pp. 869-880.

Fleisch, E. et al. (2014), Business Models and the Internet of Things, Bosch loT Lab White Paper, University of St. Gallen.

Gružauskas, V. et al. (2018), "Minimizing the trade-off between sustainability and cost effective performance by using autonomous vehicles", Journal of Cleaner Production, Vol. 184, pp. 709-717.

Guo, Z. et al. (2017), "A Timed Colored Petri Net Simulation-Based Self-Adaptive Collaboration Method for Production-Logistics Systems", Applied Sciences, Vol. 7, No. (3), pp. 235, 1-15.
Hofmann, E. and Rüsch, M. (2017), "Industry 4.0 and the current status as well as future prospects on logistics", Computers in Industry, Vol. 89, pp. 23-34.

Holmqvist, M. and Stefansson, G. (2006), "'Smart Goods' and mobile RFID A case innovation from Volvo", Journal of Business Logistics, Vol. 27, No. 2, pp. 251-272.

Janssen, M. and Feenstra, R. (2010), "Service portfolios for supply chain composition: Creating business network interoperability and agility", International Journal of Computer Integrated Manufacturing, Vol. 23, No. 8-9, pp. 747-757.

Junge, A.L. (2020), "Prospects of Digital Transformation Technologies (DTT) for Sustainable Logistics and Supply Chain Processes in Manufacturing", in Leiras A. et al. (Eds.), Operations Management for Social Good, 2018 POMS International Conference in Rio, Springer Proceedings in Business and Economics Series, Springer International Publishing. In press.

Kayikci, Y. (2018), "Sustainability impact of digitalization in logistics", Procedia Manufacturing, Vol. 21, pp. 782-789.

Kersten, W. et al. (2017), "Potenziale der Digitalisierung für das Supply Chain Risikomanagement: Eine empirische Analyse", in Seiter, M., Grünert, L., Berlin, S. (Eds.), Betriebswirtschaftliche Aspekte von Industrie 4.0, Springer Fachmedien, Wiesbaden, pp. 47-74.

Kim, H. M. and Laskowski, M. (2018), "Toward an ontology-driven blockchain design for supply-chain provenance", Intelligent Systems in Accounting, Finance and Management, Vol. 25 , No. 1 , pp. 18-27.

Lu, Y. and Ju, F. (2017), "Smart Manufacturing Systems based on Cyber-physical Manufacturing Services (CPMS)", IFAC-PapersOnLine, Vol. 50, No. 1, pp. 15883-15889.

Prause, M. and Weigand, J. (2016), "Industry 4.0 and Object-Oriented Development: Incremental and Architectural Change", Journal of Technology Management \& Innovation, Vol. 11, No. 2, pp. 104-110.

Schuh, G. et al. (2016), „Industrie 4.0: Implikationen für produzierende Unternehmen", in Gassmann, O., Sutter, P. (Eds.), Digitale Transformation im Unternehmen gestalten Geschäftsmodelle, Erfolgsfaktoren, Handlungsanweisungen, Fallstudien, Hanser, München, pp. 39-58.

Seethamraju, R. (2008), "Role of Enterprise Systems in Achieving Supply Chain Integration", International Journal of Business Insights \& Transformation, Vol. 1, No. 2, pp. 1-7.

Strandhagen, J. O. et al. (2017), , ,Logistics 4.0 and emerging sustainable business models", Advances in Manufacturing, Vol. 5, No. 4, pp. 359-369.

Stuermer, M. et al. (2017), "Digital sustainability: basic conditions for sustainable digital artifacts and their ecosystems", Sustainability Science, Vol. 12, No. 2, pp. 247-262. 
Tien, J. M. (2012), "The next industrial revolution Integrated services and goods", Journal of Systems Science and Systems Engineering, Vol. 21, No. 3, pp. 257-296.

Ward, M. et al. (2016), "Three dimensions of maturity required to achieve future state, technology-enabled manufacturing supply chains", Proceedings of the Institution of Mechanical Engineers, Part B: Journal of Engineering Manufacture, Vol. 232, No. 4, pp. 605-620.

Wernerfelt, B. (1984): "A Resource-Based View of the Firm”, Strategic Management Journal, Vol. 5, No. 2, pp. 171-180.
Yoo, Y. et al. (2010), "The New Organizing Logic of Digital Innovation: An Agenda for Information Systems Research", Information Systems Research, Vol. 21, No. 4, pp. 724-735.

Zhang, Y. et al. (2011), "Agent-based smart objects management system for real-time ubiquitous manufacturing", Robotics and Computer-Integrated Manufacturing, Vol. 27, No. 3, pp. 538-549.

Zhang, Y. et al. (2016), "Smart box-enabled product-service system for cloud logistics", International Journal of Production Research, Vol. 54, No. 22, pp. 6693-6706.

Received: 03 Mar 2019

Approved: 19 Jul 2019

DOI: 10.14488/BJOPM.2019.v16.n3.a9

How to cite: Junge, A. L. (2019), "Digital transformation technologies as an enabler for sustainable logistics and supply chain processes - an exploratory framework", Brazilian Journal of Operations \& Production Management, Vol. 16, No. 3, pp. 462-472, available from: https://bjopm.emnuvens.com.br/bjopm/article/view/813 (access year month day). 